\title{
SPATIO-TEMPORAL VARIATIONS OF SOIL WATER USE IN THE GROWING SEASON IN NORTHEAST CHINA USING MODIS DATA
}

\author{
S. Chang, F.Huang*, B. Li, H. Qi, H. Zhai \\ School of Geographical Sciences, Northeast Normal University, Renmin Street, Changchun, China - (changs164, huangf835, lib250, \\ qih102, zhaih669)@ nenu.edu.cn
}

\author{
Commission III, WG III/10
}

KEY WORDS: Soil Water Use, Gross Primary Productivity, Visible and Shortwave Infrared Drought Index (VSDI), MODIS, Spatiotemporal Pattern, Growing Season, Northeast China

\begin{abstract}
:
Water use efficiency is known as an important indicator of carbon and water cycle and reflects the transformation capacity of vegetation water and nutrients into biomass. In this study, we presented a new indicator of water use efficiency, soil water use level (SWUL), derived from satellite remote sensing based gross primary production and the Visible and Shortwave Infrared Drought Index (VSDI). SWUL based on MODIS data was calculated for the growing season of 2014 in Northeast China, and the spatial pattern and the variation trend were analyzed. Results showed that the highest SWUL was observed in forestland with the value of 36.65. In cropland and grassland, the average SWUL were 26.18 and 29.29, respectively. SWUL showed an increased trend in the first half period of the growing season and peaked around the 200th day. After the 220th day, SWUL presented a decreasing trend. Compared to the soil water use efficiency (SWUE), SWUL might depict the water use status at finer spatial resolution. The new indicator SWUL can help promote understanding the water use efficiency for regions of higher spatial heterogeneity.
\end{abstract}

\section{INTRODUCTION}

Ecosystem water use efficiency, the ratio of carbon assimilation to water loss, plays an important role in carbon and water cycles(Huang et al., 2017; Li et al., 2015). There have been some indicators presented to quantify ecosystem water use efficiency so far. Water use efficiency (WUE; GPP/ET) is a significant physiological variable and measures the tradeoff carbon gain and water loss (Kørup et al., 2018; Lu et al., 2010; Xiao et al., 2013). WUE provides the information on the ecological process and hydrological process as well (Kwon et al., 2018; Xue et al., 2015) Another ecosystem water use efficiency, namely, rain use efficiency (RUE), which is defined as the ratio of above net primary production (ANPP) to precipitation, can also help us understand the coupling between the carbon and water cycles (Huang et al., 2016; Varnamkhasti et al., 2010).

Soil moisture is vital to the environment and climate system, which influences agricultural and hydrological process, runoff generation and many other processes (Koster et al., 2004; Seneviratne et al., 2010). As the direct water source of vegetation growth and surface evapotranspiration, soil moisture is a key variable of terrestrial ecosystem. Visible/infrared satellite remote sensing technology is one of effective means to monitor soil moisture and its changes at regional and global scale. The Visible and Shortwave Infrared Drought Index (VSDI) proposed by Zhang et al. (2013b) was derived from the information of shortwave infrared (SWIR), red and blue bands. VSDI is regarded as an effective indicator of soil moisture for different surface types (Zhang et al., 2013a; Zhang et al., 2013b).

Soil moisture has decisive effect on the growth of vegetation and is closely related to ecosystem carbon dynamics (Robinson et al., 2008). More recently, soil water use efficiency (SWUE) based on gross primary productivity (GPP) and soil moisture derived from microwave remote sensing sensors has been introduced to detect ecosystem water use efficiency (He et al., 2017). Due to the low spatial resolution of the soil moisture products (with a spatial resolution of 0.25 degree), SWUE is more suitable for analysing the water use efficiency at large scale. Finer pattern of ecosystem water use efficiency and its variability may not be revealed. The feasibility of employing optical remote sensing based soil moisture information as an alternative to investigate ecosystem water use efficiency is required to be discussed. In this study, we propose a new measure of WUE, soil water use level (SWUL), computed as the ratio of GPP to VSDI and evaluate its application at a regional scale, taking the Northeast China as an example. It will help to characterize the water use efficiency for the regions of higher spatial heterogeneity.

\section{MATERIAL AND METHODS}

\subsection{Study Area}

The Northeast China (NEC) in this study is located in $115^{\circ} 32^{\prime}$ $135^{\circ} 09^{\prime} \mathrm{E}, 38^{\circ} 43^{\prime}-53^{\circ} 35^{\prime} \mathrm{N}$, covering an area of about $1.24 \times 10^{6}$ $\mathrm{km}^{2}$ (Figure 1). It belongs to a region of temperate monsoon climate with warm, rainy summers and cold, dry winters. The topography of the NEC is characterized by central plains surrounded by mountain ranges. The heartland of the region is the Northeast China Plain, which is China's largest plain and one of the three black soil regions in the world. The average elevation is lower than 200 meters. It is an important production base for food and soybean production in China. The Changbai Mountains, the Lesser Khingan Mountains and the Greater Khingan Mountains surround the plain to the east, northwest and west, respectively. The mountains are the main distribution areas of forests in Northeast China. Being the largest national natural forest region, the total forest area is about $6.8 \times 10^{5} \mathrm{~km}^{2}$, with the timber reserves of $3.2 \times 10^{9} \mathrm{~m}^{3}$.

\footnotetext{
* Corresponding author
} 


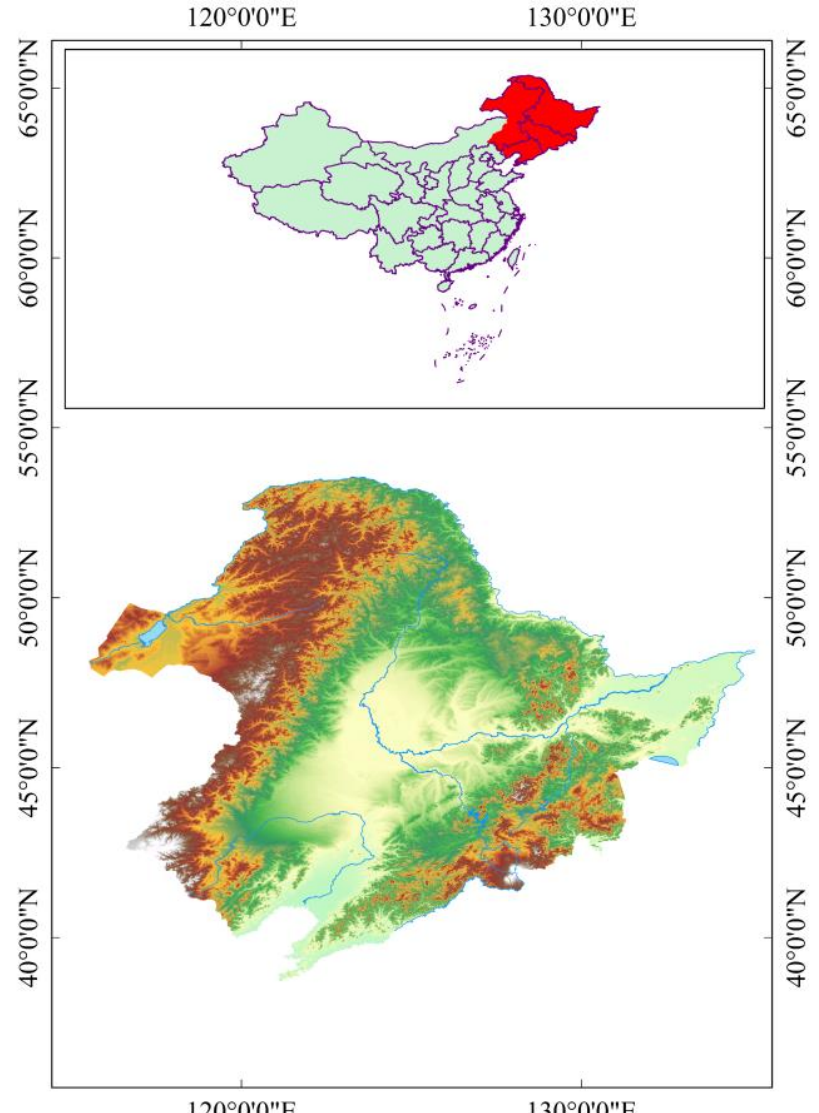

Figure 1. The Study Area

\subsection{Data and Methods}

2.2.1 Data Processing: The Terra/MODIS gross primary productivity (GPP) product (MOD17A2) is a cumulative composite of GPP values based on the radiation-use efficiency concept, which is used in the study of terrestrial carbon, water and energy cycle process. MOD17A2 data is an 8-day composite with a spatial resolution of 1-km in Sinusoidal projection. The MODIS Terra MOD09A1 product provides an estimate of the surface spectral reflectance of Terra MODIS Bands 1-7. The pixel value is selected from all the acquisitions within the 8-day composite period with a spatial resolution of $500 \mathrm{~m}$. In this study, totally 486 images of MOD17A2 and MOD09A1 in growing season (May to October) of 2014 were used, accessed at https://ladsweb.modaps.eosdis.nasa.gov/. These data were projected using MRT tools, and MOD09A1 data was resampled to a $1-\mathrm{km}$ spatial resolution so that it could match MOD17A2 data in spatial.

The global ECV soil moisture dataset supported by the Climate Change Initiative (CCI) project (http://esa-soilmoisture-cci.org/) provides daily surface soil moisture with a spatial resolution of $0.25^{\circ}$ during the period of 1978 to 2016 . The dataset has been retrievaled from active and passive microwave spaceborne instruments. It includes three products, namely, an active dataset, a passive dataset and a combined dataset, respectively. We used the combined product of soil moisture in this study. Soil moisture data during growing season in 2014 were selected due to the lack of data.
2.2.2 Calculation of VSDI: The Visible and Shortwave Infrared Drought Index (VSDI) was derived from the information of shortwave infrared (SWIR), red and blue bands. The VSDI is defined by the Equation (1):

$$
\mathrm{VSDI}=1-\left[\left(\rho_{\text {SwIR }}-\rho_{\text {Blue }}\right)+\left(\rho_{\text {Red }}-\rho_{\text {Blue }}\right)\right]
$$

where $\rho$ represents the reflectance shortwave infrared (SWIR), red and blue channels(Zhang et al., 2013b). VSDI has been proved to be highly correlated to in-situ soil moisture and regarded as an effective indicator of soil moisture for different surface types. In this study, band $1(620-670 \mathrm{~nm})$, band 3 (459$479 \mathrm{~nm})$ and band $6(1628-1652 \mathrm{~nm})$ of MOD09A1 data were adopted to calculate VSDI.

2.2.3 Calculation of SWUL: To explore the ecosystem water use efficiency based on visible/infrared information, a new measure, soil water use level (SWUL, $\mathrm{gC} / \mathrm{m}^{2}$ ) was proposed and calculated by the following equation:

\section{SWUL $=$ GPP/VSDI}

where SWUL represents the soil water use efficiency of vegetation in growing season.

Integrating the land cover data obtained from Data Center for Resources and Environmental Sciences, Chinese Academy of Sciences (RESDC) (http://www.resdc.cn), differences in average SWUL among ecosystems, aridity conditions, and latitudes during the growing season in 2014 was evaluated, respectively.

2.2.4 Correlation Analysis: Another index, namely, soil water use efficiency (SWUE, the ratio of GPP to soil Moisture) (He et al. 2017) was also calculated. We picked up 7 days from 113th day to 257th day at an interval of 24 days. Pearson's correlation analysis was employed to examine the relationship between SWUL and SWUE, and significance of correlations was assessed at $\mathrm{P}<0.01$.

\section{RESULTS}

\subsection{Spatial Pattern of GPP and VSDI in NEC}

The spatial pattern of average GPP and VSDI of the growing season in 2014 in Northeast China was shown in Figure 2. In the growing season, regional mean GPP and VSDI was $25.17 \mathrm{gC} / \mathrm{m}^{2}$ and 0.79 , respectively. The distribution of GPP has great heterogeneity, with the range from $0.00 \mathrm{gC} / \mathrm{m}^{2}$ to $84.69 \mathrm{gC} / \mathrm{m}^{2}$. The center, west and southwest of NEC had lower GPP of value (around $19.17 \mathrm{gC} / \mathrm{m}^{2}$ ), where the landforms were Songnen Plain, Liaohe Plain, Hulun Buir Plateau and southern end of Great Khingan Mountain, mainly covered by cropland, sandy land and grassland. The low GPP value was observed in Sanjiang Plain, where land cover type mainly was cropland, with the GPP value of $25.31 \mathrm{gC} / \mathrm{m}^{2}$. The region of northern Greater Khingan Mountain and the Lesser Khingan Mountain had high GPP value of $28.85 \mathrm{gC} / \mathrm{m}^{2}$. The higher GPP of $32.52 \mathrm{gC} / \mathrm{m}^{2}$ was observed in Changbai Mountains where was mainly covered by coniferous forest.

The spatial distribution of VSDI was similar to that of GPP. In most regions of center, west and southwest of NEC, lower VSDI was found. Differing from GPP, VSDI had higher value in the area where covered by river or lake in Songnen Plain and Hulun Buir Plateau. The higher value of VSDI was observed in northern of Greater Khingan Mountain, western of Lesser Khingan 
Mountain and Changbai Mountain. The VSDI values in other regions were at medium level.
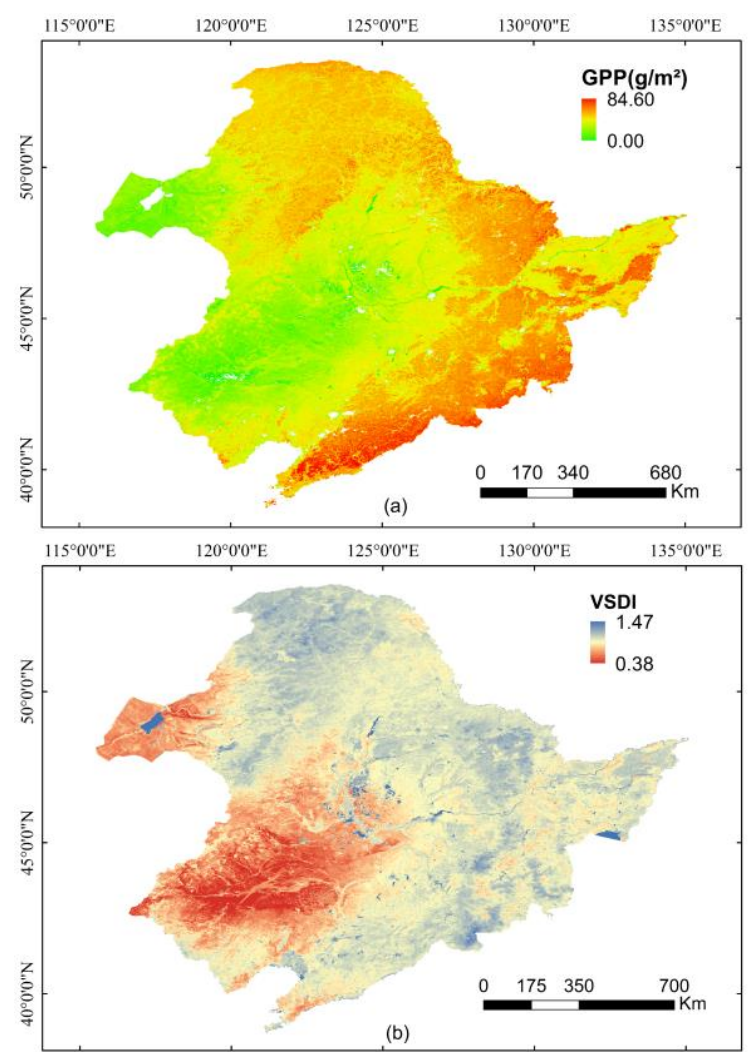

Figure 2. The distribution of GPP(a) and VSDI(b) in NEC

\subsection{Spatial distribution of SWUL}

We calculated the SWUE and SWUL of NEC in the growing season of 2014, and found that they had similar pattern. After performing the Pearson's correlation analysis, the correlation coefficient between SWUE and SWUL was $0.663,0.848,0.837$, $0.701,0.599,0.553$ and 0.718 , in the 113th, 137th, 161th, 185th, 209th, 233th, and 257th day of year, respectively.

Figure 3 shows the spatial distribution of average SWUL during the growing season in NEC. The SWUL values ranged from 0 to 98.92, of which most values were between 10 and 50. The SWUL was lower than those regions where mainly covered by cropland and grass land in the center, west and southwest of NEC. In Sanjiang Plain, located in the eastern NEC, there was higher SWUL although it was covered cropland as same as central NEC. Relatively high SWUL values were observed in the northern Greater Khingan Mountain and Lesser Khingan Mountain, showing an increasing trend from west to east. The highest SWUL values of the whole study area were found in Changbai Mountain, increasing from northeast to southwest.

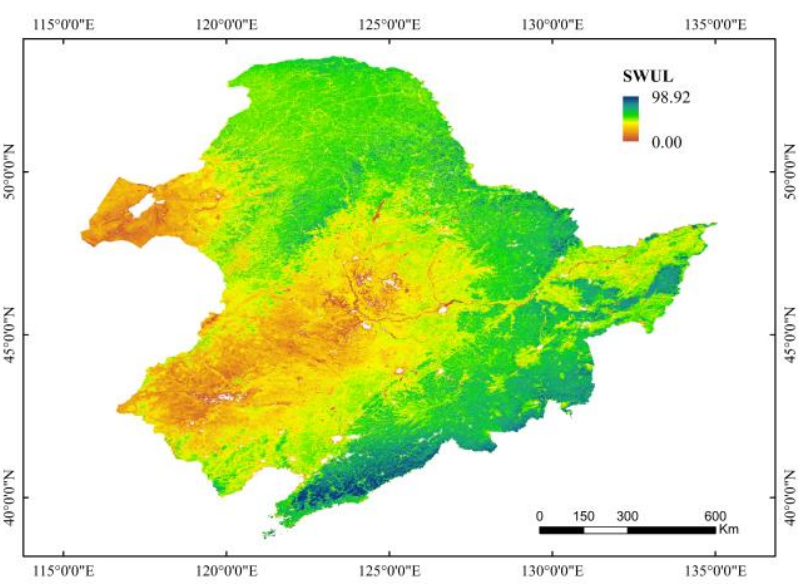

Figure 3. Spatial pattern of SWUL in NEC

\subsection{The Trend of SWUL in Growing Season}

At different periods of the growing season, there might be different SWUL. Figure 4 (a) shows the trend of the average SWUL in the NEC. The average SWUL presented the increase trend in the first half of the growing season, and it peaked around the 190th day of the year. There was a decrease trend after the 230th day. The SWUL showed a similar trend for different surface cover types (Fig.4 (b)), but the values also had many differences. For forests and grassland, the SWUL showed an increased trend in the early stage within the growing season (until to the 160th day of year). Compared to forests, the SWUL of grassland increased rapidly until about the 120th day. From the 150th and the 250th day of year, SWUL fluctuated up and down. At the end of growing season, SWUL showed a decrease trend. The SWUL of forest land was greater than that of grassland throughout the whole growing season. As for cropland, its SWUL presented an increasing trend in the first half of the growing season and it peaked around the 190th day. SWUL increased slowly at the early time of the growing season, whereas it showed a rapid increasing trend until the 130th day. The SWUL of grassland was greater than that of cropland around the 170th day of year.

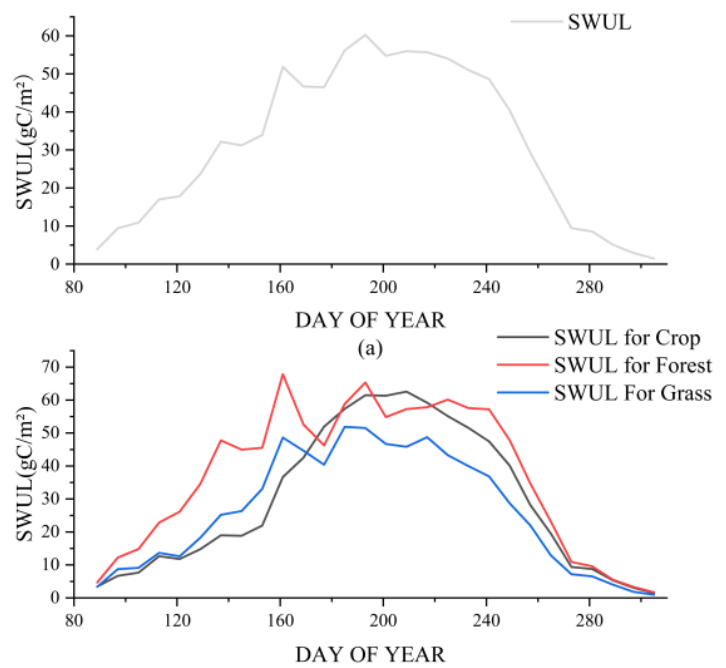

(b)

Figure 4. The trend of average SWUL in NEC(a) and the trend of SWUL (b) based on biome in the growing season 


\section{DISCUSSION}

Gross Primary Production is the sum of ecosystem photosynthetic production and is important to the study of carbon cycle (Ren et al., 2017). In this study, we analyzed the spatial pattern of GPP in NEC. Combined the data of land use, we found that the forest had greater ability of fixing the organic carbon than cropland and grassland in the study area, probably due to the larger area of the leaf for photosynthetic in the forest area. For the same land cover type, GPP in humid region (Sanjiang Plain) was greater than that in arid region (Songnen Plain), because the water deficit might be an indicator restricting the photosynthesis of vegetation. The temperature was another indicator that influenced the organic carbon accumulation of ecosystem. In Changbai Mountains, the higher GPP were observed than that in the Greater and the Lesser Khingan Mountains, which mainly because Changbai Mountains had better hydro-thermal conditions and was more favourable to vegetation growth. Some researches (Bai et al., 2008; Seneviratne et al., 2010; Wang et al., 2017; Zhang et al., 2018b) have also proved our findings.

The use efficiency of soil moisture was also investigated in this study, and we defined it as SWUL. The SWUL showed significant difference in spatial. Generally, there were higher SWUL in forests than in cropland and grassland. The possible explanation may be that the forest has more dry matter accumulation. Moreover, the latitude, temperature and the soil water content can influence the SWUL as well (Lu et al., 2010; Zhang et al., 2018a; Zhang et al., 2016). In the Changbai Mountains and the Sanjiang Plain, there were higher SWUL values than in the Lesser Khingan Mountains, northern Greater Khingan Mountains, and the Songnen Plain respectively, mainly because of the better hydro-thermal conditions.

The variation trend of soil moisture use efficiency in the growing season was also analyzed in this paper. SWUL increased and then decreased as time went on, this might because the photosynthesis of vegetation varied with the growth stages. The forest SWUL changed quickly in the early period of the growing season mainly because forests in south-eastern NEC revived earlier. The SWUL of grasslands was higher than that of cropland before the 170th day, mainly because the crops was sown later (about the 110th to 130th day). In the medium and late stage of the growing season, agricultural measures such as irrigation and fertilization might improve the SWUL of cropland (Wang et al., 2018; Zhang et al., 2018a).

\section{CONCLUSIONS}

A new index of water use efficiency, SWUL, based the MODIS GPP and VSDI data was presented and analyzed at a region scale in this study. In the growing season, the SWUL in the Northeast China showed the spatial heterogeneity. SWUL was closely related to biomes, soil moisture and temperature. Relatively high SWUL was identified in forest, and the low SWUL was observed in cropland and grassland in NEC. The better the hydro-thermal condition was, the higher the SWUL for the same type of land cover might be.

SWUL was compare with one of common index, SWUE. SWUL had the higher value and the larger range of values. There showed the similar change trend of SWUE and SWUL, but SWUL possessed the higher spatial resolution. SWUL might be more suitable for monitoring soil water use efficiency at region scale, which is important to the study of carbon and water cycle in heterogeneous regions.
SWUL presented in this paper is an indicator of the interaction between soil moisture and ecosystem productivity and it partially complemented the study of water use strategies of ecosystem. The paper presented a preliminary analysis of SWUL, and more in-depth studies, such as the applicability in other regions should be investigated in future studies.

\section{ACKNOWLEDGEMENTS}

This work was supported by the National Natural Science Foundation of China (Grant number 41571405) and the key project of the National Natural Science Foundation of China (Grant number 41630749).

\section{REFERENCES}

Bai, Y.F., Wu, J.G., Xing, Q., Pan, Q.M., Huang, J.H., Yang, D.L., Han, X.G., 2008. Primary production and rain use efficiency across a precipitation gradient on the Mongolia plateau. Ecology 89(8), pp.2140-2153.

He, B., Wang, H., Huang, L., Liu, J., Chen, Z., 2017. A new indicator of ecosystem water use efficiency based on surface soil moisture retrieved from remote sensing. Ecological Indicators 75, pp.10-16.

Huang, F., Xu, S., 2016. Spatio-Temporal Variations of RainUse Efficiency in the West of Songliao Plain, China. Sustainability 8(4), pp.308.

Huang, L., He, B., Han, L., Liu, J., Wang, H., Chen, Z., 2017. A global examination of the response of ecosystem water-use efficiency to drought based on MODIS data. Science of the Total Environment 601-602, pp.1097-1107.

Kørup, K., Laerke, P.E., Baadsgaard, H., Andersen, M.N., Kristensen, K., Münnich, C., Didion, T., Jensen, E.S., Mårtensson, L.-M., Jørgensen, U., 2018. Biomass production and water use efficiency in perennial grasses during and after drought stress. GCB Bioenergy 10(1), pp.12-27.

Koster, R.D., Yamada, T., 2004. Regions of strong coupling between soil moisture and precipitation. Science 305(5687), pp.1138-1140.

Kwon, H., Law, B.E., Thomas, C.K., Johnson, B.G., 2018. The influence of hydrological variability on inherent water use efficiency in forests of contrasting composition, age, and precipitation regimes in the Pacific Northwest. Agricultural and Forest Meteorology 249, pp.488-500.

Li, S., Kang, S., Zhang, L., Du, T., Tong, L., Ding, R., Guo, W., Zhao, P., Chen, X., Xiao, H., 2015. Ecosystem water use efficiency for a sparse vineyard in arid northwest China. Agricultural Water Management 148(C), pp.24-33.

Lu, X., Zhuang, Q., 2010. Evaluating evapotranspiration and water-use efficiency of terrestrial ecosystems in the conterminous United States using MODIS and AmeriFlux data. Remote Sensing of Environment 114(9), pp.1924-1939.

Ren, Y., Zhang, F., Kung, H.-t., Johnson, V.C., Wang, J., Zhang, Y., Yu, H., Yushanjiang, A., 2017. Using the vegetation-solar radiation (VSr) model to estimate the short-term gross primary production (GPP) of vegetation in Jinghe county, XinJiang, China. Ecological Engineering 107, pp.208-215. 
Robinson, D.A., Campbell, C.S., Hopmans, J.W., Hornbuckle, B.K., Jones, S.B., Knight, R., Ogden, F., Selker, J., Wendroth, O., 2008. Soil Moisture Measurement for Ecological and Hydrological Watershed-Scale Observatories: A Review. Vadose Zone Journal 7(1), pp.358-389.

Seneviratne, S.I., Corti, T., Davin, E.L., Hirschi, M., Jaeger, E.B., Lehner, I., Orlowsky, B., Teuling, A.J., 2010. Investigating soil moisture-climate interactions in a changing climate: A review. Earth-Science Reviews 99(3), pp.125-161.

Varnamkhasti, A.S., Milchunas, D.G., Lauenroth, W.K., Goetz, H., 2010. Production and Rain Use Efficiency in Short-Grass Steppe: Grazing History, Defoliation and Water Resource. Journal of Vegetation Science 6(6), pp.787-796.

Wang, H., He, B., Zhang, Y., Huang, L., Chen, Z., Liu, J., 2017. Response of ecosystem productivity to dry/wet conditions indicated by different drought indices. Science of the Total Environment 612, pp.347-357.

Wang, L., Palta, J.A., Chen, W., Chen, Y., Deng, X., 2018. Nitrogen fertilization improved water-use efficiency of winter wheat through increasing water use during vegetative rather than grain filling. Agricultural Water Management 197, pp.4153.

Xiao, J., Sun, G., Chen, J., Chen, H., Chen, S., Dong, G., Gao, S., Guo, H., Guo, J., Han, S., Kato, T., Li, Y., Lin, G., Lu, W., Ma, M., McNulty, S., Shao, C., Wang, X., Xie, X., Zhang, X., Zhang, Z., Zhao, B., Zhou, G., Zhou, J., 2013. Carbon fluxes, evapotranspiration, and water use efficiency of terrestrial ecosystems in China. Agricultural and Forest Meteorology 182183(22), pp.76-90.

Xue, B.-L., Guo, Q., Otto, A., Xiao, J., Tao, S., Li, L., 2015. Global patterns, trends, and drivers of water use efficiency from 2000 to 2013. Ecosphere 6(10), pp.1-18.

Zhang, D., Li, R., Batchelor, W.D., Ju, H., Li, Y., 2018 a. Evaluation of limited irrigation strategies to improve water use efficiency and wheat yield in the North China Plain. PLoS One 13(1), e0189989.

Zhang, J., Jiang, H., Song, X., Jin, J., Zhang, X., 2018b. The responses of plant leaf $\mathrm{CO} 2 / \mathrm{H} 2 \mathrm{O}$ exchange and water use efficiency to drought: a meta-analysis. Sustainability 10(2), pp.551-563.

Zhang, N., Hong, Y., Qin, Q., Zhu, L., 2013a. Evaluation of the visible and shortwave infrared drought index in China. International Journal of Disaster Risk Science 4(3), pp.68-76.

Zhang, N., Hong, Y., Qin, Q.M., Liu, L., 2013b. VSDI: a visible and shortwave infrared drought index for monitoring soil and vegetation moisture based on optical remote sensing. International Journal of Remote Sensing 34(13), pp.4585-4609.

Zhang, T., Peng, J., Liang, W., Yang, Y., Liu, Y., 2016. Spatialtemporal patterns of water use efficiency and climate controls in China's Loess Plateau during 2000-2010. Science of the Total Environment 565, pp.105-122. 